
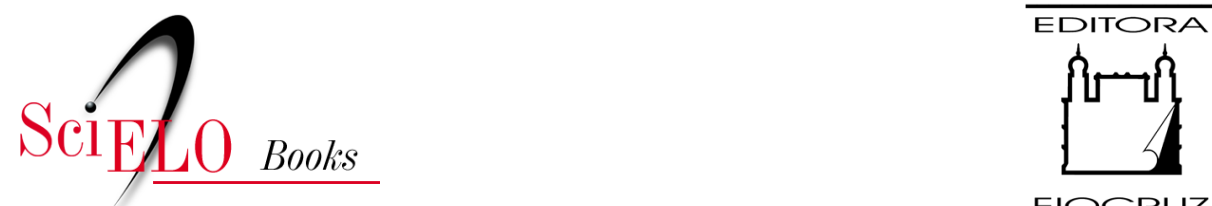

FIOCRUZ

\title{
Prefácio à primeira edição
}

\author{
Raymundo Moniz de Aragão
}

\section{SciELO Books / SciELO Livros / SciELO Libros}

ARAGÃO, R.M. Prefácio à primeira edição. In: FRAGA, C. Vida e Obra de Oswaldo Cruz [online]. 2nd ed. Rio de Janeiro: Editora FIOCRUZ, 2005, pp. 15-22. ISBN: 978-65-5708-099-3. https://doi.org/10.7476/9786557080993.0003.

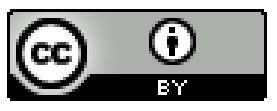

All the contents of this work, except where otherwise noted, is licensed under a Creative Commons Attribution 4.0 International license.

Todo o conteúdo deste trabalho, exceto quando houver ressalva, é publicado sob a licença Creative Commons Atribição 4.0.

Todo el contenido de esta obra, excepto donde se indique lo contrario, está bajo licencia de la licencia Creative Commons Reconocimento 4.0. 


\section{PREFÁCIO À PRIMEIRA EDIÇÃO}

Am simples lance de olhos sôbre as vidas de clementino Fraga e Osvaldo de haverem conduzido, a duas décadas de intervalo, campanhas vitoriosas contra a febre amarela, nesta mesma cidade, bela e sofrida. Mas, isto é o acidental, o fato exterior que, se os envolve no mesmo preito de admiração agradecida dos brasileiros, por forma alguma justifica a condiçāo em que nesta obra se associam e, de certa forma, se confrontam.

o que realmente comove o leitor iniciado e o induz a uma comparaçāo inevitável dos dois grandes vultos, à margem do texto que, nobre cautela do autor, só raramente em curtas passagens a sugere, é a forma semelhante por que sentem e solvem os episódios que lhes salteiam a ação de dirigentes sanitários, em país subdesenvolvido. Isto, não por cópia intencional ou falta de imaginação, mas pelo afeiçoamento, no mais mô̧̧o, da forma de pensar e agir à do homem tão bem compreendido e tão intensamente admirado, a que se ligou por sincera afeiçāo, para logo idealizada na saudade, a jeito de filiação espiritual.

Para quem conhece a vida dos dois eminentes brasileiros, suas lutas, suas obras, é uma experiência avassaladora ver emergir, por fôrça de simples confrontação, de uma cronologia morta de fatos epidemiológicos, incidentes administrativos, ocorrências triviais, todo o processo - gradativo, vivo, palpitante de sentimento - através do qual, em metamorfoses, por dizer inevitáveis, o conhecimento suscitou a admiração, esta propiciou a afeiçăo nobilitante, motivadora a seu turno de um propósito subconsciente de identificação que não se esgota na observân- 
cia do modêlo, antes procura fixá-lo, em rememoração grata, e tenta a interpretação do personagem, na projeção da própria personalidade.

De Osvaldo Cruz e Fraga, não há exagêro em falar de filiaçăo, pois, nascidos embora a distância menor que dez anos, a diferença de idade, menos expressiva em têrmos biológicos, representa, no ápice da parábola que figura a trajetória profissional, o passo de uma geração. No caso, o intervalo entre a geração que presenciou as grandes descobertas da nascente medicina experimental e a aplicação das incipientes e revolucionárias normas sanitárias dela emergentes, e a que assistiu o emprêgo desenvolto de tais medidas, acreditadas em êxito espetacular, pelo recuo constante das grandes endemias, afinal represadas nas áreas menos desenvolvidas, à espera do golpe final que as elimine.

De Fraga, ouvi certa feita, que "não há filhos adotivos, mas pais adotados", a significar ser o sentimento filial que efetivamente realiza e consagra a filiação volitiva. Dêle, também, li, na sua bela e pessoal forma de escrever, a propósito do comércio de geraçōes: “[....] o ensino é a amizade! [....] Amizade que se faz no respeito mútuo, na comunhão pacífica, concorde nos mesmos interêsses e superiormente discorde de quaisquer subalternidades; [.... amizade que se edifica na confiança recíproca e prolonga, fora da família, a família intelectual, sob mágicos auspícios de numes estranhos e desconhecidas afinidades." É, de fato, a linhagem espiritual, onde a afeição tece os laços que encadeiam os elementos clonais e enseja, à margem de imperativos genéticos, a identificação perseguida.

Quando Fraga chegou ao Rio, em 1906, vindo de Salvador onde, três anos antes, se diplomara com notas máximas e tese de doutoramento festejada em têrmos retumbantes, recrutava Osvaldo Cruz, através de provas rigorosas de seleção, talentos moços movidos, acima de tudo, pelo prestígio da tarefa sanitária, elevada a nivel de cruzada redentora. Fraga, tentada a clínica particular em Campo Grande e Piedade, por um pouco, na aspereza das primeiras escaramuças, em busca de lugar ao sol no ambiente altamente competitivo da metrópole, que lhe sugerira já ao bom senso os subúrbios distantes, deixou-se atrair e ingressou nas hostes de Osvaldo, como inspetor sanitário, devidamente concursado, como hoje se diz, na linguaguem daspiana.

Tinha Osvaldo Cruz - então jovem diretor cuja autoridade se impunha ao govêrno e à opinião pública, e cujo prestígio avultava entre os da classe, ao ímpeto de arrojadas e corretas medidas sanitárias que começavam a limpar, das manchas 
pestilenciais, a fisionomia da capital brasileira - quanto preciso para incendiar a admiração do jovem médico e conquistar-lhe a afeição devota: a mocidade nimbada da auréola precoce de sábio, a autoridade espontânea e direta, que vem da confiança na própria decisão e da certeza intuitiva de ser obedecido, a intrepidez no agir valorizada pela reflexāo e pelo saber profissional, o desinterêsse pelo imediato, a visāo comedida da glória. Sobretudo, a coragem estóica em face da incompreensão, a honestidade intransigente em matéria científica, o patriotìsmo esclarecido a nortear a ação pública.

Na realidade, Osvaldo Cruz empolgou, em Fraga, a necessidade de admirar, que Rui Barbosa ressalta existir em todo homem. Admirou-o êste com exaltação, de forma a compor do chefe o exemplo, do exemplo o nume tutelar, tudo favorecido pela convergência de naturezas conformes, voluntariosas e refletidas, mais acentuada ainda pela mesma educação em rígidos princípios de honra e dever, o mesmo fervor à profissão comum, a comum vocação de grandeza.

Mas, ainda nessas condiçōes excepcionais, a admiração só, do mais môço, não faria dêste, sucessivamente, o auxiliar, o amigo, o êmulo, o biógrafo. Era necessário que fôsse, como de fato ocorreu, Identificada e retribuída em aprêço e confiança. A admiração desapercebida é, mais das vêzes, como a semente da parábola, caída em terra pobre: floresce por um pouco e estiola-se. A perenidade do sentímento admirativo exige o orvalho da afeiçāo retribuída.

Já não participou, Fraga, da fase heróica da campanha, cumprida que fôra, a duras penas, entre os anos de 1903-1906, a promessa audaciosa do intrépido diretor, de eliminar, no prazo de três anos, a epidemia de febre amarela, do Rio de Janeiro. Mas, teve lugar, sob a direção de Osvaldo Cruz, nos trabalhos de consolidaçăo da vitória obtida, depois abandonados, em hora inglória, o que ensejou o ressurgimento do morbo, em 1928. Capacitou-se então, dos métodos idôneos empregados pelo grande sanitarista e, mais ainda, imbuilu-se do seu pensamento, onde o rigor do critério científico não excluíra a aquisição nova, em ortodoxia estática e impermeável, mas, ao contrário, incentivava a captação de novos conhecimentos, no aprumo da observação vigilante, de modo a favorecer a realização de avanços técnicos.

Assim foi que, na segunda campanha contra a febre amarela, ao lado dos métodos avalizados na vitoriosa empreitada de Osvaldo, empregou Fraga a vaporização de derivado de petróleo, em substituiçāo à desinsetização fúmea, pelo enxôfre. 
E corrigiu, por igual, a noção consagrada desde as experiências de Queimados, em Cuba, que fixava em mais de sete dias o ciclo evolutivo do mosquito, mostrando poder ser êste encurtado, em clima tropical e estação calmosa. Com o que erigiu nova prática, ao reduzir a duração do periodo em que se repetia o expurgo dos focos identificados, assim obviando os percalços do reaparecimento do pernilongo rajado em locais tidos por limpos.

Da primeira experiência de Fraga, em atividades sanitárias, sob as ordens e em contato com Osvaldo Cruz, advieram-lhe o aprêço e a a feição dêste. Atestam-no, os têrmos da dedicatória aposta por Osvaldo em retrato oferecido ao jovem colega e prestimoso auxiliar, de retôrno à terra natal, para submeter-se a concurso, visando a ser provido em cátedra vaga da gloriosa Faculdade de Medicina da Bahia. Sāo expressões que, de muito, excedem as fórmulas convencionais da polidez e revestem o tom inconfundível de sincera amizade, edificada no julgamento favorável da capacidade profissional e na simpatia de atributos intelectuais e éticos.

Mas, não foram a imagem e palavras gravadas em papel que tornaram inesquecíveis e sagrados, para Fraga, o exemplo e a lembrança de osvaldo. Foi, ouso afirmá-lo, em interpretação temerária, mas assente em intuição não desmentida na observaçăo de muitos e muitos anos, o dramático e pouco conhecido incidente do vapor Araguaia, o fator decisivo a influenciar Fraga na fixação do exemplo a seguir, de então para sempre.

Em tarde aflita - uma provocação nunca vem só, dìz o adágio - corria o verão baiano de 1910, recebe Fraga, à beira do leito do primogênito enfềrmo, mensagem telegráfica do diretor do Departamento Nacional de Saúde Pública, solicitando-lhe embarcar naquele navio da Mala Real Inglêsa, fundeado ao largo de Salvador, com casos de cólera a bordo, para proceder as medidas sanitárias necessárias à salvaguarda do Rio de Janeiro, seu pôrto de escala obrigatória, da importação do terrível morbo asiático. Permite-se Fraga, apenas, consultar o inspetor do pôrto de escala obrigatória, da importação do terrível morbo asiático. Permite-se Fraga, apenas, consultar o inspetor do pôrto de Salvador, sôbre se deseja êle tomar a si a missão, no reconhecimento de que há riscos profissionais que, competindo a outro, não se pode assumir sem consulta, sob pena de ofensa grave e lesāo da ética. Negativa a resposta, embarca Fraga altas horas da noite, a cumprir a missão de forma tão eficiente que passa ao perigo despressentido do público e favorece o seu rápido esquecimento por parte das autoridades aliviadas, satisfeitas em regular o assunto com pequena 
paga - dez contos de réis, por quarenta e cinco dias e quarenta e cinco noites de exposiçăo ao contágio mortífero - e ofício protocolar de agradecimento.

Mas, Fraga é que não esqueceu, jamais, ser de Osvaldo Cruz a inspiraçāo da medida e a indicação do seu nome para o desempenho da missão arriscada e cheia de responsabilidade. E, porque a cumpri-la nāo estava obrigado, pois já não mantinha laços com o serviço sanitário de que se desligara, e a convocação insólita refletia, por isso, aprêço singular ao profissional e confiança irrestrita no cidadão; e, porque a desempenhou bem, sobrepassando temores de riscos pessoais advertidos na lembrança da espôsa e da filha, e de insucesso profissional estimado em têrmos de sofrimento de uma grande cidade, foi-lhe grato, para sempre, pela indicação, que o distinguira, como o homem à altura da missão crucial.

A partì daí, a solidariedade incondicional, embasada em provada confiança. $\mathrm{E}$, sobrevindo a morte de Osvaldo Cruz, nove anos depois, inicia-se o processo de identificação, para logo favorecido pela provação nas mesmas dificuldades e idênticos sofrimentos, crescente na admiração que a ausência valoriza e nada mais pode corromper.

Assim, quando o destino arrasta Fraga de retôrno às atividades sanỉárias, após interregno em funçōes docentes e parlamentares, e o submete às mesmas rudes provas a que sujeitara osvaldo, de máximo dirigente sanitário em oportunidade de surto epidêmico, ocorre o que se poderia esperar: a sua conduta irrepreensível reedita o exemplo do mestre. Reproduzidas as circunstâncias, repetem-se atos e atitudes, não por cópia, repito, mas pela conformidade do processo de sentir, julgar e proceder.

Desde logo, experimenta a luta surda, informe - de oposição não formalizada e resistência macia - que oferece ao maior esfôrço requerido e às inovaçōes necessárias, a tríade malsã que, à feição de figuras apocalípticas, assombra a autoridade, em momentos que tais: a rotina, a ignorância e a má fé. Há, então, que se lhes opor a decisăo voluntariosa, na forma de normas claras e corretamente prescritas, cobrada a observância com exigente empenho, sem consideração a díficuldades ou contingências.

Encontrados, ainda, focos de estegomia, após advertência pontual, na Hospedaria da Ilha das Flôres, ponto sensível e explosivo, dada a concentração de elementos estrangeiros não imunes, decide Fraga, por impera tivo de exemplo, a imediata substituição do chefe do serviço. A medida comove, pois alcança profissio- 
nal experiente; esboça-se movimento de solidariedade, a que Fraga acode, com a destituição sumária dos dissidentes, segundo a formula osvaldiana, a que tantas vêzes se reporta - "sem quebrar, sem torcer" - que colima, sem desvios, o objetivo, marginalizando os recalcitrantes, deixando atrás os timoratos e acomodatícios.

Quando lhe vêm dizer que o govêrno impacientava-se já, ante a imobilidade do placar, que reproduzia semanalmente os mesmos números, de novos casos e de óbitos causados pela febre amarela, tarda em atender as providências adotadas, necessariamente ainda frouxas pois alargadas, no ímpeto do surto epidêmico, até a área suburbana do Rio de Janeiro, responde Fraga indo apresentar ao ministro, pedido de novos e vultosos recursos. Era a forma de, sem explicitar, pôr sôbre a mesa a questão de confiança; era, mutatis mutandi a repetição do gesto de Osvaldo Cruz, advertido de que seria perigoso insistir no ponto de vista que adotara - de abandonar a desinfecçāo das vestes, vômitos e dejeçōes de amarelentos, por inócua e onerosa - em vista da celeuma levantada, na imprensa leiga e nas tribunas médicas, e que molestava o govêrno, indo reclamar ao ministro, e do próprio presidente, recursos, com a opção do seu afastamento do cargo. É bem conhecida a resposta à interpelação presidencial, se já não tinha fé na doutrina do mosquito... "Fé absoluta, Sr. Presidente, mas faltam-me recursos para o pagamento dos mata-mosquitos." Em ambos os casos, os recursos vieram, oportunos na aplicação e na reafirmação da confiança questionada. E, comenta Fraga, "então, os governos prometiam e cumpriam...".

Por surpreendente que pareça, vencidas a rotina e a ignorância, persiste a malícia, onde e como pode, no propósito nefasto de dificultar a ação da autoridade sanitária. Provou-lhe, Fraga, o fel amargo e venenoso, na forma de insidiosa e impatriótica campanha jornalística apostada em cobrar, em detrimento da verdade e dos foros culturais do país, prejuízos impostos a interêsses subalternos.

Não se distanciou, Fraga, no silêncio ante o ataque inidôneo, e na informação diutuma à opinião pública, da verdade sem retoque - através de boletins sucintos e números exatos - da conduta de Osvaldo, sob iguais circunstâncias. Sāo de Barbosa Lima Sobrinho, ainda sob a emoção de sua morte, os seguintes comentários: "Êsse fol o grande mérito de Clementino Fraga: o de ser verdadeiro, o de ser exato e corajoso. $O$ de evítar manifestações de vanglória. $O$ de não perder substância no trabalho de encobrir uma realidade que tinha a fôrça de uma evidência. $E$ mesmo quando a vitória parecia assegurada, retardar as manifestaçōes de triunfo 
para o momento em que tudo se convertesse numa certeza, sem possibilidade nem de êrro, nem de fraude."

Mas, a insídia tem formas de agressão ainda mais sutis e molestas quando a inspiram o despeito e a pusilanimidade. Assim, a memória de Osvaldo Cruz, erguida por Fraga à altura de exemplo inspirador de cada hora, vai servir a mofinos detratores, na maneira obliqua de ferir, que consiste em elogiar sem medida a outrem, para deprimir pelo confronto. Escreveu Fraga, a propósito, em nobre e magoado registro:

"Vinte anos rodados, em nova incursão epidêmica da febre amarela no Rio de Janeiro, pelo descaso dos governos que sucederam a Rodrigues Alves, $o$ ambiente de hostilidade ràpidamente se formou para contrariar a açāo da autoridade sanitária, nāo mais para combater a doutrina já suficientemente julgada, mas para negar capacidade ao diretor. Por essa ocasião os feiticistas da memória benemérita de Osvaldo Cruz formaram em côro contra o chefe da Saúde Pública. Era o "louvor deliberado contra alguém", como disse Afrânio Peixoto, a propósito de casos dêsses tais, muito de gôsto da hostilidade encoberta, mal disfarçada na debilidade do ataque."

o silêncio pundonoroso, se nobilita, oprime e amarga. Săo, ainda, de Barbosa Lima Sobrinho, os seguintes comentários:

"Administrar com uma imprensa livre e sem perigos é, na verdade, combater, todos os dias, num corpo-a-corpo, em que a inteligência e o êxito se desafiam, num trabalho em que a crítica vale mais do que aplausos, como auxílio, como alerta, como cooperação. E Clementino Fraga reagiu esplêndidamente, nāo obstante o profundo desencanto, que êle não sabia dissimular e que fazia dêle um leitor assíduo do Eclesiastes."

Faz-se, entāo, compreensivel que êste homem, por tanto tempo fechado em contido silêncio, se deixasse arrastar, no ato de exaltaçāo do vulto admirado, ao encontro da necessidade de exteriorizar sentimentos e juízos reprimidos, falando de outro, para prevenir a deselegância, molesta à compostura pessoal, de usar da primeira pessoa.

o livro inspirado por propósito de sentimentos que êste obscuro discípulo assim pensou entrever, é o livro póstumo que surge, a tempo e hora, quando transcorre, com fraca ressonância, o centenário de Osvaldo cruz. Servirá êle a recordar, não os feitos de um, mas de ambos, vultos gigantescos de um díptico a ornar a paisagem do sanitarista brasileiro. 
De suas vidas tāo conformes, apenas uma discrepância sensível há que apontar - o tempo por que se alargaram. Quarenta e três anos viveu Osvaldo Cruz; Fraga ultrapassou a casa dos noventa.

Do desaparecimento de Osvaldo Cruz, mal chegado ao meio-dia da existência, disse Fraga: "A morte prematura, parecendo atalhar uma carreira gloriosa, não permitiu que a vida lhe desmaiasse a glória." De Fraga se pode dizer, na contemplação da longa estrada percorrida sem contradiçães ou desfalecimentos, que a morte tardia serviu a edificar o raro exemplo de uma vida de trajetória retilínea, que despontou para a glória e, sem inflexão, consumiu-se na distância.

Rio de Janeiro, 17 de fevereiro de 1972.

Raymundo Moniz de Aragāo 